\title{
Review of a Case of Paraquat Poisoning in a Tertiary Care Rural-based ICU
}

\author{
Deepak S Sharma ${ }^{1}$, Abhishek M Prajapati ${ }^{2}$, Dhruv M Shah ${ }^{3}$
}

\begin{abstract}
Paraquat (1,1'-dimethyl-4, 4'-dipyridylium) is a broad-spectrum liquid herbicide associated with both accidental and intentional ingestion leading to severe and often fatal toxicity. ${ }^{1}$ Paraquat is actively taken up against a concentration gradient into lung tissue leading to pneumonitis and lung fibrosis. Paraquat also causes renal and liver injury. ${ }^{2}$ There are few case publications of paraquat poisoning and only few of them have reported that renal failure has ensued before acute respiratory distress syndrome (ARDS). Our patient presented with above lethal dose intake of paraquat containing substance and we did gastric lavage followed by charcoal hemoperfusion and hemodialysis but patient could not be saved despite optimum efforts suggesting the high fatality of this kind of poisoning.

Keywords: ARDS, Charcoal hemoperfusion, Paraquat poisoning

Key Messages: Acute renal injury with hypoperfusion state due to toxicity at cellular level, redox cycling and intracellular reactive oxidative stress generation may also cause death in early stages in paraquat poisoning despite optimal management.

Indian Journal of Critical Care Medicine (2019): 10.5005/jp-journals-10071-23182
\end{abstract}

\section{INTRODUCTION}

This case report is of a young male presented to "Shree Krishna Hospital, Karamsad, Anand" with alleged history of intentional consumption of paraquat containing substance (gramoxone). Despite adequate measures, we lost the patient early but not due to acute respiratory distress syndrome (ARDS), which is the common cause of death in patients with paraquat poisoning. We have searched two of the biggest databases Medline and PubMed and found more than 800 articles, case reports and few case series related to paraquat poisoning. But only less than ten of them mentioned that patient suffered early acute kidney injury before ARDS.

\section{Case History}

A 26-year-old male with no known comorbidities presented to trauma and emergency care with alleged history of intentional consumption of around $35 \mathrm{~mL}$ of paraquat containing substance (gramoxone) (Figs 1 and 2) at around 8:15 am at his home, which was followed by three episodes of vomiting. There was no history of convulsions, ear nose throat (ENT) bleed or loss of consciousness.

Patient was bought to the emergency room at around 9:30 am and his vital parameters were: heart rate of 100 beats per minute with respiratory rate of 20 breaths per minute, maintaining oxygen saturation of $95 \%$ in room air, and blood pressure of $140 / 80 \mathrm{~mm} \mathrm{Hg}$.

\section{On Systemic Examination}

- Respiratory system was clear on auscultation bilaterally and no adventitious sounds were heard,

- Cardiovascular system: S1S2 normal, no rub/gallop/murmur

- Central nervous system: GCS $15 / 15$, pupils bilaterally equally reacting to light, no focal neural deficit

- Abdominal examination: Soft and nontender

\section{Investigations Trend}

Bedside ultrasound abdomen and pelvis was grossly within normal limits. Blood results are shown in Table 1.
${ }^{1}$ Department of Critical Care, King's College Hospital, London, United Kingdom

${ }^{2,3}$ Department of Critical Care, Shree Krishna Hospital, Karamsad, Anand, Gujarat, India

Corresponding Author: Deepak S Sharma, Department of Critical Care, King's College Hospital, London, United Kingdom, e-mail: deepu84in@ gmail.com

How to cite this article: Sharma DS, Prajapati AM, Shah DM. Review of a Case of Paraquat Poisoning in a Tertiary Care Rural-based ICU. Indian J Crit Care Med 2019;23(6):284-286.

Source of support: Nil

Conflict of interest: None

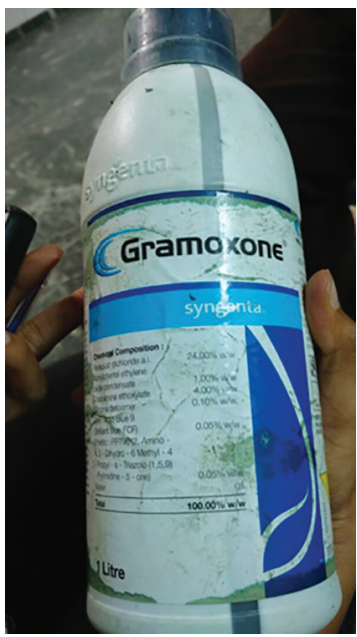

Fig. 1: Bottle of paraquat containing liquid gramoxone

As soon as the patient was presented to the emergency room, gastric lavage with $\mathrm{KMnO}_{4}$ was given. Patient was then transferred to the intensive care unit where urgent charcoal hemoperfusion and hemodialysis were initiated. Patient remained

(-) The Author(s). 2019 Open Access This article is distributed under the terms of the Creative Commons Attribution 4.0 International License (https://creativecommons. $\mathrm{org} / \mathrm{licenses} / \mathrm{by}-\mathrm{nc} / 4.0 /$ ), which permits unrestricted use, distribution, and non-commercial reproduction in any medium, provided you give appropriate credit to the original author(s) and the source, provide a link to the Creative Commons license, and indicate if changes were made. The Creative Commons Public Domain Dedication waiver (http://creativecommons.org/publicdomain/zero/1.0/) applies to the data made available in this article, unless otherwise stated. 
Review of a Case of Paraquat Poisoning in a Tertiary Care Rural-based ICU

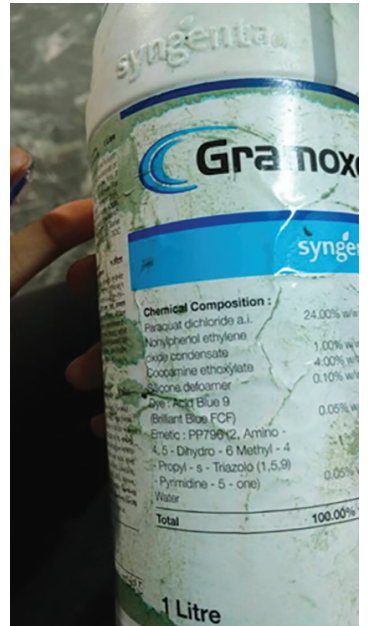

Fig. 2: Contents of paraquat containing liquid gramoxane

hemodynamically and neurologically stable during the dialysis. He was also treated with $\mathrm{N}$-acetyl cysteine as antioxidant and other supportive medications. Investigations revealed metabolic acidosis with hyperlactatemia. On the next day, patient progressively developed hypotension along with oliguria. He was intubated in view of deteriorating hemodynamics and was kept on mechanical ventilatory support with vasopressor support. Another session of hemodialysis was done. Patient had persistent hypotension despite high dose vasopressor support and he suffered cardiac arrest at around 12:30 am on the 3rd day of admission, cardiopulmonary resuscitation (CPR) was done as per advanced cardiac life support (ACLS) protocol, but could not be revived and declared dead.

\section{Discussion}

Paraquat (1, 1'-dimethyl-4, 4'-dipyridylium) is a broad-spectrum liquid herbicide associated with both accidental and intentional ingestion leading to severe and often fatal toxicity. ${ }^{1}$ Paraquat generates reactive oxygen species which cause cellular damage via lipid peroxidation, activation of NF- $\mathrm{KB}$, mitochondrial damage, and apoptosis in many organs. Kinetics of distribution into these target tissues can be described by a two-compartment model. Paraquat is actively taken up against a concentration gradient into lung tissue leading to pneumonitis and lung fibrosis. Paraquat also causes renal and liver injury. ${ }^{2}$

The methods to counter poisoning include both hemodialysis and hemoperfusion, anti-inflammatory agents and antioxidants. There have been measures taken to reduce toxicity of paraquat by adding compounds to the herbicide while some countries have banned the herbicide altogether. Diagnosis might be difficult due to lack of proper history and unavailability of diagnostic tests.

Literature review revealed few case reports from India, compared to paraquat poisoning being widely reported from elsewhere. Poisoning with paraquat leads to both local and systemic effects. In an Indian series of 17 patients, the most common symptoms were vomiting (100\%), followed by altered sensorium $(59 \%)$, oral ulceration or dysphagia $(53 \%)$, dyspnea $(41 \%)$, or loose stools (24\%). ${ }^{3}$ Systemic effects of paraquat are renal and hepatic failure, pulmonary oedema and fibrosis, cardiac failure, shock, convulsions, and multiorgan failure. Involvement of lung in the form of diffuse alveolitis, and subsequent pulmonary fibrosis is
Table 1: Blood results

\begin{tabular}{|c|c|c|c|}
\hline & $24 / 4 / 17$ & & $25 / 4 / 17$ \\
\hline$A B G$ & & $5 \mathrm{pm}$ & \\
\hline $\mathrm{pH} /$ lactate $(\mathrm{mmol} / \mathrm{L})$ & $7.34 / 7.9$ & & $7.42 / 2.1$ \\
\hline $\mathrm{pCO}_{2} / \mathrm{pO}_{2}(\mathrm{~mm} \mathrm{Hg})$ & $36 / 101$ & & $29 / 110$ \\
\hline $\mathrm{HCO}_{3}(\mathrm{mmol} / \mathrm{L})$ & 19.4 & & 18.8 \\
\hline Base excess (mmol/L) & -5.7 & & -4.6 \\
\hline S. $\mathrm{Na}^{+}(\mathrm{mmol} / \mathrm{L})$ & 145 & 140 & 145 \\
\hline S. $\mathrm{K}^{+}(\mathrm{mmol} / \mathrm{L})$ & 4.5 & 4.6 & 2.8 \\
\hline S. cholinesterase (U/L) & 16425 & & \\
\hline CRP (mg/L) & 6.7 & & \\
\hline S. creatinine (mg/dL) & 1.14 & 3.40 & 5.06 \\
\hline $\mathrm{TC}(\mathrm{x} 1000 / \mu \mathrm{L})$ & 10 & & 8 \\
\hline $\mathrm{Hb}(\mathrm{g} / \mathrm{dL})$ & 13 & & 10.6 \\
\hline PC (/UL) & 372,000 & & 100,000 \\
\hline INR/PT & $1.01 / 11.7$ & & $1.93 / 22.80$ \\
\hline \multicolumn{4}{|l|}{ LFT } \\
\hline Bilirubin/D/I (mg/dL) & $0.72 / 0.19 / 0.53$ & & $2.12 / 1.3 / 0.82$ \\
\hline SGPT/SGOT (U/L) & $34 / 38$ & & $50 / 89$ \\
\hline S. alk-P (U/L) & 80 & & 37 \\
\hline S. amylase & & & 231 \\
\hline Lipase & & & 2508 \\
\hline
\end{tabular}

the hallmark of paraquat poisoning. Acute respiratory distress syndrome because of paraquat usually appears 24-48 hour after ingestion. ${ }^{4}$

Poisoning by herbicide paraquat is a common cause of selfpoisoning in vast parts of south-east Asia including India. ${ }^{5}$ The very high case fatality due to inherent toxicity and lack of effective treatment is somewhere between $50 \%$ and $90 \% .{ }^{6}$ Gramoxone contains $24 \%$ paraquat dichloride, $1 \%$ cocoamine ethoxycar, $0.1 \%$ silicone defoamer, $0.05 \%$ acid blue dye, PP796, and pyrimidine $5 .{ }^{7}$ Paraquat has been shown to cause significant damage to organs, including the lung, liver, myocardium and kidneys with the highest concentration of paraquat found in the lungs. ${ }^{8}$

A paraquat dose of $30 \mathrm{mg} / \mathrm{kg}$ may be fatal, which is equivalent to $8-10 \mathrm{~mL}$ of the $20 \%$ solution sold commercially. ${ }^{9}$ Our patient was given IV fluid resuscitation of $2.5 \mathrm{I}$ bolus followed by $100 \mathrm{~mL} / \mathrm{hour}$ with normal saline. As patient was not hypoxic initially, so he was not started on oxygen therapy. Initial gastrointestinal decontamination was done with activated charcoal $30 \mathrm{gm}$ in water via a nasogastric tube which is according to published treatment protocols. ${ }^{2}$

Our patient had normal kidney function on the day of admission and underwent hemoperfusion and hemodialysis. In spite of this, the patient developed acute kidney injury on 2 nd day of admission. The patient did not improve and developed hypotension on the second day on high dose vasopressors but had cardiac arrest on the third day and expired in spite of CPCR. Patient X-ray was normal throughout the period of hospital admission and patient did not develop hypoxia. These suggest that the patient did not develop acute respiratory distress syndrome, which is the most common cause of death in patients with paraquat poisoning. In our patient, acute kidney injury was the cause of death. Also, in our patient, kidney was involved before the lung, normally either 
the lung and kidney are involved together or the lung is involved before the kidney. ${ }^{10}$

Another important observation was that in spite of doing hemofiltration, hemodialysis within 4 hours as recommended, patient developed acute kidney injury which led to his death.

\section{Conclusion}

In conclusion, our case report emphasizes that it is not only ARDS that kills in paraquat poisoning, renal failure with hypoperfusion state may also cause death in early stages in paraquat poisoning.

\section{References}

1. Khosya S, Gothwal S. Two cases of paraquat poisoning from Kota, Rajasthan, India. Case Rep Crit Care. 2012;2012:652146. doi: $10.1155 / 2012 / 652146$

2. Gawarammana IB, Buckley NA. Medical management of paraquat ingestion. Br J Clin Pharmacol. 2011;72(5):745-757. doi: 10.1111/j.13652125.2011.04026.x

3. Sandhu JS, Dhiman A, Mahajan R, Sandhu P. Outcome of paraquat poisoning-a five year study. Indian J Nephrol. 2003;13:64-68.
4. Singh S, Bambery P, Chaudhry D, Makharia G, Kakkar N, Singh D. Fatal paraquat poisoning: report of two cases. J Assoc Physicians India. 1999;47(8):831-832.

5. Gunnell D, Eddleston M, Phillips MR, Konradsen F. The global distribution of fatal pesticide self-poisoning: systematic review. BMC Public Health. 2007;7(1):357. doi: 10.1186/1471-2458-7-357

6. Senarathna L, Eddleston M, Wilks MF, Woollen BH, Tomenson JA, Roberts DM, et al. Prediction of outcome after paraquat poisoning by measurement of the plasma paraquat concentration. QJM: Int J Med. 2009;102(4):251-259. doi: 10.1093/qjmed/hcp006

7. Dhadwad J, Shiddapur G, Borawake K, Patil H. Rapid onset pulmonary fibrosis due to paraquat poisoning. Medical Journal of Dr. DY Patil University. 2014 Jul 1;7(4):482-485. doi: 10.4103/0975-2870.135277

8. Weng CH, Hu CC, Lin JL, Lin-Tan DT, Huang WH, Hsu CW, et al. Sequential organ failure assessment score can predict mortality in patients with paraquat intoxication. PloS One. 2012;7(12):e51743. doi: 10.1371/journal.pone.0051743

9. Yang CJ, Lin JL, Lin-Tan DT, Weng CH, Hsu CW, Lee SY, et al. Spectrum of toxic hepatitis following intentional paraquat ingestion: analysis of 187 cases. Liver Int. 2012;32(9):1400-1406. doi: 10.1111/j.14783231.2012.02829.x

10. Sittipunt C. Paraquat poisoning. Respir Care 2005; 50:383-385. 